A R T I G O

\title{
CASA dOS AÇORES DE SÃo PAULO: IMIGRAÇÃO, ASSOCIATIVISMO E RELIGIOSIDADE
}

São Paulo’s Azores house: immigration, associativism and religiosity

Casa de las Azores de São Paulo: inmigración, asociativismo y religiosidad

\author{
ELIS Regina BARBOSA ANGELO ${ }^{*}$ \\ MARIA IZILDA SANTOS DE MATOS ${ }^{11^{* *}}$
}

http://dx.doi.org/10.1590/S2178-14942018000300007

\footnotetext{
I Pontifícia Universidade Católica de São Paulo (PUC-SP), São Paulo - SP, Brasil.

*Pós-doutora em História pela Pontifícia Universidade Católica de São Paulo, Professora Adjunta nos cursos de Bacharelado em Turismo da UFRRJ, na Licenciatura em Turismo no Consórcio CEDERJ/ EaD e no Programa de Pós-graduação em Patrimônio, Cultura e Sociedade, PPGPACs da UFRRJ. (elis@familiaangelo.com)

" Pontifícia Universidade Católica de São Paulo (PUC-SP), São Paulo - SP, Brasil.

** Pós-doutora pela Université Lumiere Lyon, França e Doutora em História pela Universidade de São Paulo. Atualmente é Professora Titular da Pontifícia Universidade Católica de São Paulo. (mismatos@pucsp.br)
}

Artigo recebido em 24 de maio de 2018 e aceito para publicação em 10 de setembro de 2018. 


\section{RESUMO}

Esta investigação focaliza as experiências dos imigrantes açorianos na cidade de São Paulo, em particular sua prática associativa na Casa dos Açores de São Paulo (Casp), observando sua historicidade, o cotidiano, as atividades recreativas e assistenciais, além das ações voltadas para a manutenção das tradições, memórias, religiosidade e festividades, como a do Divino Espírito Santo, um dos ícones desse grupo de imigrantes.

PAlaVRAS-CHAVE: Casa dos Açores de São Paulo; Imigração; Associativismo; Sujeitos históricos.

\section{ABSTRACT}

This research focuses on the experiences of the Azorean immigrants in the city of São Paulo, in particular, their associative practice in the Casa dos Açores de São Paulo (Casp), observing their historicity, daily life, recreational and assistance activities, as well as actions aimed at maintaining the traditions, memories, religiosity and festivities such as the Divine Holy Spirit, one of the icons of this group of immigrants.

KEYWORDS: São Paulo's Azores House; Immigration; Associativism; Historical subjects.

\section{RESUMEN}

Esta investigación se centra en las experiencias de los inmigrantes azorianos en la ciudad de Sao Paulo, en particular, su práctica asociativa en la Casa de las Azores de Sao Paulo (Casp), observando su historicidad, el cotidiano, actividades recreativas y asistenciales, además de acciones dirigidas al mantenimiento de las actividades tradiciones, memorias, religiosidad y festividades como la fiesta del Divino Espíritu Santo, uno de los iconos de ese grupo de inmigrantes.

Palabras ClaVE: Casa de las Azores de São Paulo; Inmigración; Asociativismo; Sujetos históricos. 


\section{UM TERRITÓRIO ${ }^{1}$ AÇORIANO: VILA CARRÃO (SP)}

presença de açorianos no Brasil pode ser localizada em vários estados (Maranhão,
Bahia e Rio de Janeiro), com destaque para Santa Catarina e Rio Grande do Sul, nos quais o contingente foi mais significativo. ${ }^{2}$ Em São Paulo, as referências aos açorianos são imemoriáveis, enfatizando a presença de famílias da ilha de São Miguel em fazendas na região de Ribeirão Preto (de propriedade de Martinho Prado Jr.), também em Descalvado, Mogi Mirim, Campinas e Piracicaba - estes se deslocaram nos anos finais do século XIX.

O fluxo de açorianos para São Paulo se manteve constante no século XX, sendo intensificado a partir das décadas de 1950 e 1960 pelas novas possibilidades da expansão econômica e urbana ${ }^{3}$ (Angelo e Matos, 2008). Na cidade, eles se instalaram na Vila Carrão (zona Leste da cidade), nas redondezas das ruas Dentista Barreto, Água Funda e Luzia da Conceição Moraes, que ainda hoje apresentam um número elevado de ilhéus e seus descendentes (Matos, 2013).

O estabelecimento dos açorianos se deu, na maioria das vezes, por oportunidades de trabalho, como as do Cotonifício Guilherme Giorgi, ${ }^{4}$ no qual ocupavam a maior parte dos postos. Além dessa ocupação, esses imigrantes se dedicaram às ocupações em setores técnicos especializados, fazendo-se presentes em padarias, armazéns, floriculturas, feiras livres e açougues, participando de forma ativa e garantindo a visibilidade na comunidade da Vila Carrão.

Gradativamente, estabeleceu-se um sistema de atração que funcionava por redes: ${ }^{5}$ os recém-chegados ou os que eram chamados tinham indicações para a inserção na fábrica:

Primeiro veio meu tio, minha tia e duas primas, e depois nós viemos, ah... o meu pai e minhas duas irmãs, depois a minha mãe e quatro filhas, e depois ainda mais um tio, que morou na nossa casa... O meu pai e as minhas duas irmãs, quando chegaram aqui, o meu tio já tinha arrumado um serviço na tecelagem de Guilherme Giorgi, que geralmente [era] onde todos trabalhavam... Meu pai trabalhou sempre em indústria e nessa tecelagem, na Cotonifício Guilherme Giorgi, [que] chamava. E trabalhava também fazendo horta, todo pedaço de terra que ele via. Tinha um campo aí do Guilherme Giorgi que eram tudo casa, sobrados, apartamentos, que tinha ali, que os portugueses se juntavam ali naquele pedaço de terra e cultivavam ali. E isso, e o meu pai trabalhava de noite na fábrica e durante o dia ele pegava as verdurinhas dele, botava num carrinho de mão e ia vender na feira. (Depoimento de Maria de Lurdes Arruda Paz, 2 /nov. 2006)

A cidade de São Paulo crescia em diversas direções, incluindo a zona Leste, área com presença destacada do setor industrial e de uma mão de obra imigrante. Nesse contexto: 
0 crescimento urbano definira o zoneamento social de São Paulo. As áreas baixas, de várzeas e periféricas ao centro, sujeitas às diversas catástrofes naturais, e onde o preço da terra, por consequência, era menor, destinavam-se à instalação industrial e à habitação proletária, proximidade que rebaixava o custo de transporte da força de trabalho, desse modo imediatamente acessível. [...] o Brás sofreu, talvez mais que qualquer outro bairro da Capital, uma brutal intervenção humana no ambiente natural que dotou-o, [sic] da noite para o dia, das qualidades e mazelas de outra singular natureza: a da sociedade industrial. Justamente ali ergueram-se, [sic] durante as quatro últimas décadas do século passado, os equipamentos mais avançados produzidos pela indústria contemporânea, desde a implantação da malha ferroviária, capaz de transportar mercadorias e força de trabalho de um lado para o outro, cobrindo grandes distâncias em muito menos tempo, até as primeiras fábricas de médio e grande porte da Capital paulista, principalmente as do setor têxtil, constituindo-se, assim, num polo de atração irrefutável para imigrantes [...]. (Verona, 1999: 15-16)

Os imigrantes estabeleciam relações na dinâmica do crescimento urbano, em um cotidiano marcado por atividades de trabalho e de lazer. 0 Cotonifício, de certa forma, foi o primeiro elo entre os açorianos e seus conterrâneos, pois, ao atraí-los para o Brasil por meio de redes de amigos e parentes, também fortaleceu laços de amizade, conterraneidade, parentesco e vizinhança, especialmente nos bairros operários. Assim, pode-se dizer que o trabalho foi um dos motes da constituição dessas redes de colaboração e vínculos de trabalho e sociabilidade. Muitos dos que vieram por cartas de chamada tinham parentes ou conterrâneos que auxiliavam no estabelecimento na cidade; já outros, que haviam vindo sós, encontraram vínculos no bairro e na fábrica.

0 desejo de organizar uma associação surgiu diante da necessidade de apoio e auxílio, não só na procura por trabalho, mas também na inserção na sociedade de acolhimento, seja no que se refere à educação, saúde, cotidiano e religião, seja nas práticas de sociabilidade que se formavam. Pode-se perceber a concentração de esforços e cooperação entre os sujeitos históricos que a conceberam, constituindo-se a partir do anseio de compartilhar as relações de sociabilidade e agrupar os conterrâneos que vieram para o Brasil em busca de oportunidades. ${ }^{6}$ Nesse contexto, a Casa dos Açores foi uma iniciativa de membros da comunidade de açorianos, visando a preservar expressões culturais e tradições (música, festas, gastronomia, saberes e religiosidade), tornando-se uma forma de demarcar seu espaço/território.

Assim nasceu a proposta da organização da Casa dos Açores, que, ao ser institucionalizada (receber a conotação de instituição), foi regulamentada por meio "de elementos reguladores, normativos e cultural-cognitivos, que, juntos com atividades associadas e recursos, fornecem estabilidade e significado à vida social" (Scott, 2008: 48).

A esse respeito, tem-se seu primeiro estatuto: 
CAPÍTULO I - Da Denominação, Fundação e Fins

Artigo $1^{0}$

A CASA DOS AÇORES DE SÃO PAULO, fundada aos 22 de junho de 1980, é uma pessoa jurídica de direito privado, com personalidade distinta de seus sócios sem fins lucrativos, com sede e foro nesta cidade, à Rua Dentista Barreto, № 1282, Vila Carrão, e tem por finalidade:

I - Promover, anualmente, a Festa do Divino Espírito Santo, que realizar-se-á em sua sede;

II - Promover e divulgar a cultura, as tradições e os costumes açorianos;

III - Promover o congraçamento de todos os açorianos, familiares e associados;

IV - Promover periodicamente reuniões de caráter social, cultural e recreativo e afins, em harmonia com o disposto nos itens anteriores;

V - Manter uma biblioteca educacional;

VI - Fomentar a prática desportiva, bem como manter o intercâmbio com órgãos e entidades análogos, nacionais e internacionais. (Casa dos Açores de São Paulo, 1995: 2)

Esse estatuto levou algum tempo para ser efetivado, pois as ideias e ações de associativismo foram sendo construídas gradativamente, articulando elementos capazes de agregar os açorianos à Casa, também estratégias de aproximação com o governo dos Açores e de outros imigrantes de diversas localidades pelo mundo na diáspora açoriana.

0 Governo Regional das Comunidades dos Açores ${ }^{7}$ assume, entre suas missões, a de articular as Casas da comunidade açoriana espalhadas pelo mundo, mantendo laços e reavivando a memória e as identidades. ${ }^{8}$ A Casa dos Açores de São Paulo mantém elos com o governo dos Açores, recebendo apoio e ajuda na organização de atividades.

Em sua trajetória, a Casa concentrou ações que extrapolam as premissas de sua fundação, enfrentou desafios similares aos de outras instituições, uma vez que a "[...] função original das casas regionais de agregar os imigrantes e atuar como lugares de memória tem se perdido em muitas situações pela simples questão da sobrevivência das Instituições" (Oliveira, 2014: 16).

Os açorianos que trabalhavam no Cotonifício Guilherme Giorgi se reuniam para contar histórias e rememorar a terra natal, além de outros momentos de encontro na fábrica, igreja e festejos de rua, como nas festas juninas. Nessas ocasiões, emergiu o desejo de fundar uma capela para glorificar o Espírito Santo. Assim, pode-se dizer que, entre outros elementos, a Casa se originou do anseio dos açorianos de alocar as festividades e seus símbolos, especialmente a Festa do Divino Espírito Santo e a do Senhor Santo Cristo dos Milagres, que são devoções muito difundidas nas ilhas. 
Nesse sentido, destaca-se que os movimentos de associativismo tinham função relevante na legitimação da cultura e da religiosidade. Além disso, o intuito associativista ${ }^{9}$ buscava a formação de um território que possibilitasse fortalecer traços culturais diluídos no processo de deslocamento e pelos ocultamentos na metrópole de São Paulo, marcada pela diversidade cultural, com a presença de muitos grupos de imigrantes e migrantes.

Sobre a criação da Casa dos Açores, o sr. Manuel de Medeiros (3/6/2008), um dos que mais se envolveram nessa empreitada, rememora quando os açorianos da Vila Carrão se reuniam para debater as possibilidades de fundar uma associação açoriana. 0 depoente destaca como os envolvidos na fundação enfrentaram dificuldades quanto à falta de apoio, espaço e recursos financeiros. Assim, inicialmente se estabeleceram na garagem do sr. José Vitorino de Arruda, na Rua Zodíaco, onde começaram a celebrar a Festa do Divino. Aos poucos, foram inserindo novos sujeitos ao grupo e formaram uma primeira diretoria, tendo como presidente o sr. Manuel de Medeiros, um agente da construção e disseminação da cultura açoriana na cidade.

A Casa dos Açores de São Paulo foi criada em 22 de junho de 1980 por um grupo de açorianos residentes na Vila Carrão e funcionava inicialmente numa garagem à Rua Zodíaco, cedida pelo açoriano José Vitorino de Arruda. Neste dia formou-se a primeira diretoria, tendo como presidente o empresário/engenheiro Manuel de Medeiros. Em novembro de 1981, a sede foi transferida para uma antiga casa adquirida na Rua Dentista Barreto, 1.282. 0 projeto de construir a nova sede mobilizou as mais de 50 famílias que participaram da organização da Casa com doações em dinheiro e com trabalho. (Freitas, 2006: 166)

A concepção da Casa foi articulada por diálogos entre conterrâneos, que, sabendo da existência de outras instituições, procuravam reproduzir essas experiências. Alguns membros da comunidade já estabelecidos no bairro e com contatos nos Açores (especialmente na Ilha de São Miguel) trouxeram para a cidade símbolos da tradição ${ }^{10}$ religiosa e buscaram uma retomada das práticas deixadas quando da partida das ilhas.

O primeiro a dirigir a Casa foi o empresário/engenheiro Manuel de Medeiros, que ocupou a presidência durante cinco gestões, de 22/06/1980 a 11/07/1987. 0 segundo, Manuel Henrique Farias Ramos, ficou no cargo de 11/07/1987 a 9/07/1989, e o terceiro, Manuel Pereira Arruda, de 9/07/1989 a 6/7/1991. 0 quarto presidente, Antonio Mendes Cardoso Sequeira, ficou na presidência duas gestões, de 28/8/1992 a 24/06/1995. 0 sexto presidente foi Elisiário dos Santos Filho, que ocupou o cargo durante duas gestões, de 22/06/1996 a 29/06/2000. (Freitas, 2006: 167)

A Casa dos Açores traz entre seus principais objetivos a função social e cultural, a promoção de eventos (visando a angariar fundos para a manutenção das atividades e da própria Casa) e o desenvolvimento do que chama "identidade cultural", dando particular atenção à 
Festa do Divino Espírito Santo, considerada importante elo com as origens. Em depoimento do Senhor Manuel de Medeiros (3/6/2008), percebe-se a importância das festividades desde os primórdios da criação:

Já estávamos construindo a Casa dos Açores. Então, foi a primeira festa que foi feita em frente à Casa dos Açores, foi a minha. Foi legal. Geralmente, tudo que se faz lá eu sou geralmente 0 pioneiro, tudo leva meu apreço, tudo que eu puxo o negócio pra ver se aquele está mais sério que 0 anterior. Porque a gente estava na frente das casas dos mordomos, estava muito ruim, não dava pra fechar a rua, então não se tinha mais controle. Então, eu passei em 82, eu passei justamente pra Casa dos Açores, onde se faz os festejos, e dali pra frente foi sempre na Casa dos Açores. E como objetivos, a Casa dos Açores de São Paulo visa reunir os açorianos, os seus descendentes e todos os simpatizantes da região, bem como manter e propagar a cultura, o folclore e os usos e costumes dos Açores. 0 objetivo maior da entidade é a realização a cada ano da Festa do Divino Espírito Santo, de acordo com os rituais e calendário da região da Bretanha na llha de São Miguel.

Durante a construção da sede, estreitaram-se os vínculos entre os sujeitos históricos que participaram diretamente das obras (com trabalho e/ou financiamento). Desse modo, constituíram-se memórias capazes de fomentar atividades e fortalecer laços de amizade, união e identificação. 0 esforço se justificava no sentido da construção de um território pensado para manter "viva" a religiosidade, o companheirismo, as tradições familiares e as concepções de vida de seus antepassados. Fortaleceria ainda o elo com os Açores e com os conterrâneos estabelecidos em São Paulo, favorecendo a manutenção da memória e da cultura que tivessem um denominador comum nas relações sociais e religiosas da crença e devoção ao Divino Espírito Santo.

Apesar das dificuldades, a missão de abraçar a cultura açoriana e buscar identificação, união, motivação e manutenção de vínculos entre os membros do grupo foi assumida. Além de cultivar as tradições açorianas, a Casa propiciava sociabilidade e reencontros de amigos, conterrâneos e parentes, buscando manter conexões com as origens por meio das festas religiosas, atividades e eventos programados. A empreitada da construção contou com apoio coletivo, organização de tarefas e atividades executadas pelo grupo em um esforço que fortaleceu ações, ampliando desejos e lapidando os objetivos associativos. 


\section{Imagem 1 - Construção da Casa dos Açores de São Paulo}

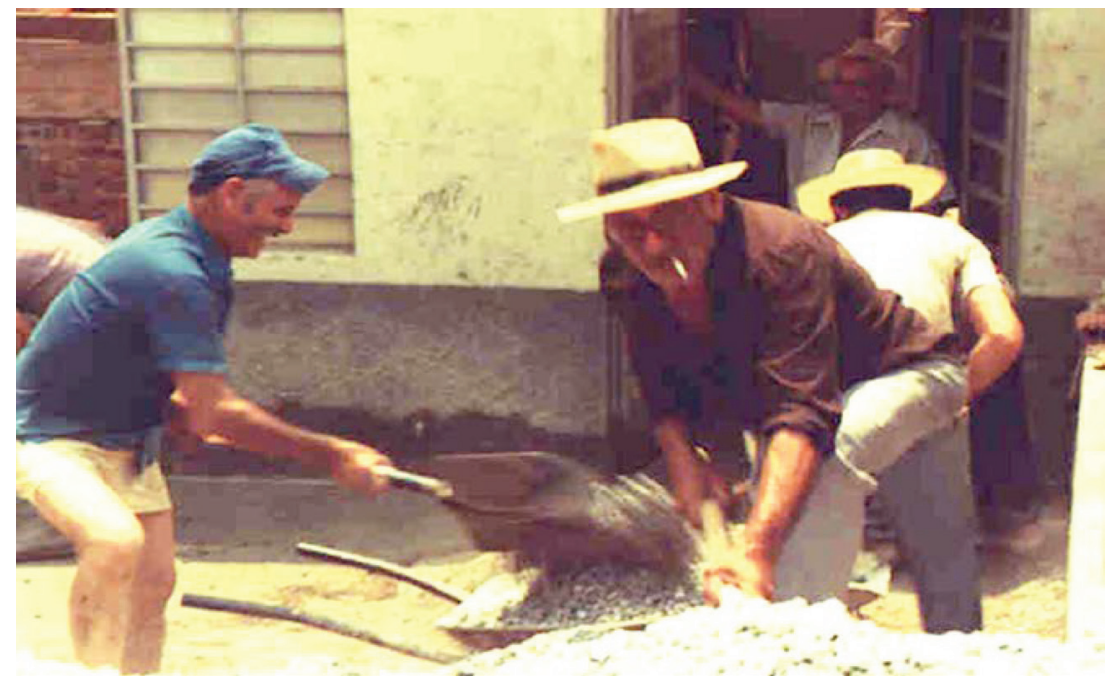

Fonte: Acervo da Casa dos Açores de São Paulo.

A 24 de julho de 1979, alguns idealistas da colônia açoriana de Vila Carrão reuniram-se com a finalidade de fundar uma associação açoriana, onde todos os açorianos e seus descendentes pudessem reunir-se para um bate-papo agradável e recordar a terra distante. Era necessário encontrar um lugar para a sede, pois precisávamos de uma capela para a festa do Espírito Santo, que já era celebrada desde 1975. Assim, a 22 de junho de 1980, é fundada a Casa dos Açores, numa humilde garagem sita à rua Zodíaco, cedida com tanto carinho por um açoriano, sr. José Vitorino de Arruda, e forma-se a primeira diretoria, tendo como primeiro presidente o engenheiro Manuel de Medeiros. Finalmente, a 21 de abril de 1986, é oficialmente inaugurada esta instituição, com a presença de João Bosco Mota Amaral, presidente do Governo Regional dos Açores da altura, do exmo. e revmo. d. Luciano Mendes de Almeida, bispo da Região Episcopal Belém, que presidiu a Eucaristia e abençoou a casa. Presentes também estiveram Manuel de Medeiros, presidente, e toda a diretoria, assim como grande parte de associados e convidados. (Depoimento de Antonio Tavares Arruda, 21 jan. 2018) 
Imagem 2 - Inauguração da Casa dos Açores de São Paulo

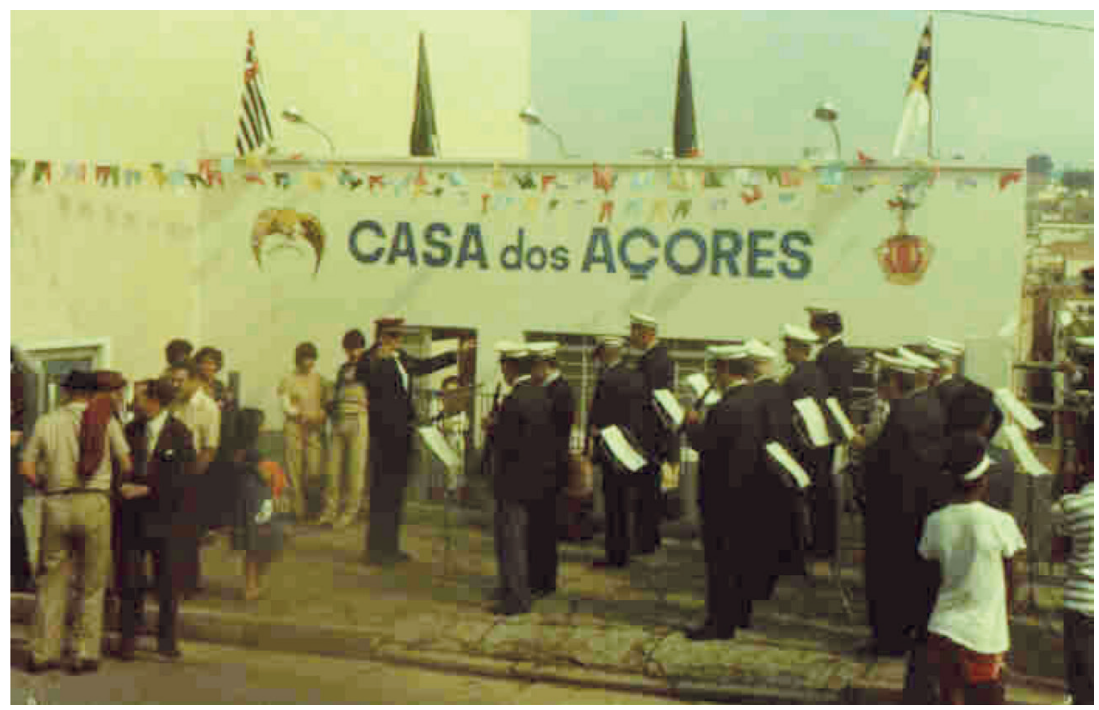

Fonte: Acervo da Casa dos Açores de São Paulo.

Diferentemente das associações mutualistas e de socorros mútuos, ${ }^{11}$ as casas e associações regionais ${ }^{12}$ de estrangeiros surgiram em momento em que os imigrantes necessitavam de auxílio para inserção na sociedade de chegada.

Apesar de seu caráter recreativo, um dos objetivos mais respeitados pelas associações portuguesas - inclusive pelas Casas Regionais — é a orientação e introdução dos novos imigrantes no mercado de trabalho e na vida urbana (a maioria dos portugueses vem de áreas rurais). Por outro lado, elas pretendem reproduzir no Brasil símbolos e padrões culturais característicos de Portugal ou das regiões portuguesas que representam. (Seyferth, 1990: 67)

Essa forma de associativismo deve ser entendida como uma troca, mas também como prática política, pois se inscreve em uma arena de tensões permanentes, relações de dominação, negociações e trocas (Rocha-Trindade, 2010).

Nesse processo de constituição, foram diversas as ações culturais, sociais e religiosas, destacando-se entre as atividades mais relevantes a organização do grupo folclórico, das festas religiosas, das atividades de lazer, de recreação e de comensalidade. Dessa forma, mediante esse conjunto de ações, a Casa dos Açores foi inscrevendo sua marca no bairro e na cidade, praticando e divulgando costumes, tradições e hábitos açorianos. 
A instituição promove um conjunto de iniciativas e eventos gastronômicos, com pratos e produtos típicos dos Açores, palestras, exposições e outros eventos, com primazia para as artes, como teatro, dança, música e sessões de poesia. 0 ápice dos seus eventos culturais são as semanas culturais, que ocorrem a cada ano, envolvendo, para além da comunidade, escolas e alunos da região. A cada ano se adota um tema em torno de qual se desenvolve toda a sua programação, por meio de dança, teatro, exposição de trabalhos, palestras e afins. 0 tema adotado normalmente enseja aspectos comuns entre Brasil e Portugal, e, não raro, temas que envolvem o planeta, nações e demais comunidades emigradas do estado de São Paulo. Portanto, considera-se que a Casa dos Açores de São Paulo tem desenvolvido um trabalho de divulgação dos Açores (aos mais variados níveis) junto a estudantes do ensino universitário e ensino básico através da dinamização de sessões de esclarecimento e concursos variados, sendo de mencionar o concurso "Açores, Natural, Naturalmente e Brasil Florão da América", iniciado na Semana Cultural de 2012, que envolveu um concurso de redações sobre a temática, no qual participaram várias escolas, e um quiz para apuramento do vencedor. Este concurso teve como prêmio uma viagem de uma semana aos Açores, que ocorreu em novembro de 2013 e foi organizada pela Direção Regional das Comunidades. (Depoimento de Antonio Tavares Arruda, 21 jan. 2018)

As atividades organizadas ocorriam em colaboração e buscavam agregar interesses coletivos. Desse modo, foi criado um calendário anual, que estabelece os eventos de entretenimento para associados e colaboradores, proporcionando formas de inter-relação com visitantes, convidados e outros interessados em participar das festividades. Emblemático é o caso das Festas do Divino, durante as quais ocorrem quermesses, com a presença dos associados e de um público externo que também participa dos festejos. Outras festas também atraem visitantes, como os jantares da "Noite de Malassadas" e as bacalhoadas, bem como os bingos promovidos para angariar fundos para a organização das atividades da Casa.

\section{EXPERIÊNCIAS E AÇÕES: MANUTENÇÃO DA ASSOCIAÇÃO E FESTA DO DIVINO ESPÍRITO SANTO}

s experiências coletivas foram estreitando elos entre os integrantes da Casa, particular-
mente os articulados nas celebrações, ações festivas, gastronômicas e nos eventos de cunho religioso. Na Vila Carrão, os açorianos constituíram seu território, deixando marcas de suas tradições pelas ruas desse bairro. ${ }^{13} \mathrm{Na}$ sede e no entorno da Casa dos Açores, realizam-se festas e quermesses, e de lá saem as procissões (Divino Espírito Santo), cujo trajeto corta a avenida Conselheiro Carrão, uma das mais importantes da área.

Os depoimentos referendam essa territorialidade e rememoram as experiências sobre a fundação da Casa dos Açores, os sujeitos históricos envolvidos, as práticas cotidianas ${ }^{14}$ na associação e as formas de celebrar. Quando recuperam suas histórias, os açorianos narram-nas 
com o coração; apesar de recriá-las sob suas próprias perspectivas, tratam das memórias como algo fundamentado em um passado que, mesmo distante, engloba boa parte de suas vidas.

Eu fiz uns versinhos aqui para a Casa dos Açores. Então, tem até uma parte da minha vida... Meu namoro, como é que eu cheguei a morar aqui. Para falar a verdade, não ficou com ninguém. Porque aquilo é uma coisa minha, eu fazia e me sentia emocionada, eu li, até hoje não consigo ler para os outros, eu só leio pra mim, então, aquilo era uma coisa que vinha de dentro, que me recordava... o que eu escrevo, parece que eu estou começando a viver de novo, entendeu? Então, aquilo, pra mim, é muito estimado. (Depoimento de Maria Joana Rezende Rodrigues, 2 out. 2008)

As reminiscências reconstroem elos entre o passado saudoso e as melhores memórias, que se encontram formatadas em bons e maus momentos. Embora façam parte de uma história total, as pessoas acabam selecionando aspectos de que gostam de lembrar.

Antes da fundação da Casa dos Açores de São Paulo, neste mesmo local havia um clube, e, se me lembro, chamava-se "Lusitano", onde as festas juninas eram organizadas. Faziam os arraiais enfeitados com "bambu" e bandeirolas de papel colorido. 0 evento atraía muitos casais de namorados e jovens para as brincadeiras. Depois é que veio a Casa dos Açores de São Paulo, que, de certa forma, formalizou todo o ritual e toda a cerimônia com relação às atividades do Divino Espírito Santo. A casa foi fundada na década de 80 do século passado. A partir de então, o culto ao Divino Espírito Santo, no dia de Pentecostes, tomou vulto e alcança o sucesso que é hoje. (Depoimento de Henrique de Arruda Soares, 7 jul. 2008)

Quando relata suas lembranças de infância, o sr. Henrique enfatiza as festas juninas, que, segundo ele, eram realizadas no mesmo local onde hoje está instalada a Casa dos Açores. Já ao rememorar o estabelecimento da Casa, referências à Festa do Divino emergem a todo momento, e nessas lembranças o espaço-tempo da festa representa uma forma de ligar-se ao passado por "lugares de memória" que possibilitam recordações dos tempos de infância, dos momentos mais relevantes, como as festas juninas e as brincadeiras sempre presentes na formação das memórias (Nora, 1993: 9).

É com estima que são realizadas as celebrações e festas aqui no Brasil. Tanto dedicadas ao Senhor Santo Cristo dos Milagres, à Nossa Senhora de Fátima, onde estão presentes nas nossas cerimônias religiosas. Por não haver espaço suficiente na sede da Casa dos Açores, obtemos autorização e apoio da nossa prefeitura regional para ocupação da via pública. No dia 13 de maio, dedicado a Nossa Senhora de Fática, é rezada a missa. É em um único dia de dedicações, então são lembrados e se fazem presentes na procissão do Divino Espírito Santo. As imagens do Senhor de Santo Cristo e a de Nossa Senhora de Fátima, e do Espírito Santo, representado pelas sete coroas e [pela] Bandeira do Divino, estão sempre presentes nas cerimônias religiosas e festas. Faço questão de ser um membro para carregar o andor do Senhor Santo Cristo e de 
Nossa Senhora de Fátima. Este ano de 2008 não carreguei, por me encontrar lá nos Açores. (Depoimento de Henrique de Arruda Soares, 7 jul. 2008)

Percebe-se a produção de sentidos dada às experiências vivenciadas, às memórias constituídas e reforçadas pelos marcos escolhidos da origem que conformaram representações da comunidade imaginada ${ }^{15}$ em terras distantes.

$\mathrm{Na}$ articulação entre ação (fazer histórico) e representação (reprodução social) reside a possibilidade de recuperar analiticamente a dinâmica das relações sociais, afirmando o caráter criativo dos universos simbólicos que se concretiza nos modos como se inserem em campos de práticas. Desse modo, a cultura é sempre processo, em constante reatualização. Todo e qualquer ato dos sujeitos de ações significantes corresponde à dinamização do universo cultural: reposição, reelaboração ou alteração dos sentidos existentes. (Garcia, 1996: 6)

Nos Açores, as festividades, celebrações e comemorações religiosas passam por processos históricos de ressignificação. Da mesma forma, as festividades e celebrações na cidade de São Paulo promovidas pela Casa também precisam ser observadas em sua historicidade, atentando para as diferenciações, sendo exemplar a questão dos bodos, ${ }^{16}$ que na capital paulista adquiriram cunho filantrópico, feitos em prol de hospitais, clínicas e demais instituições do bairro da Vila Carrão e de suas adjacências.

\section{Imagem 3 - Almoço na Casa dos Açores de São Paulo}

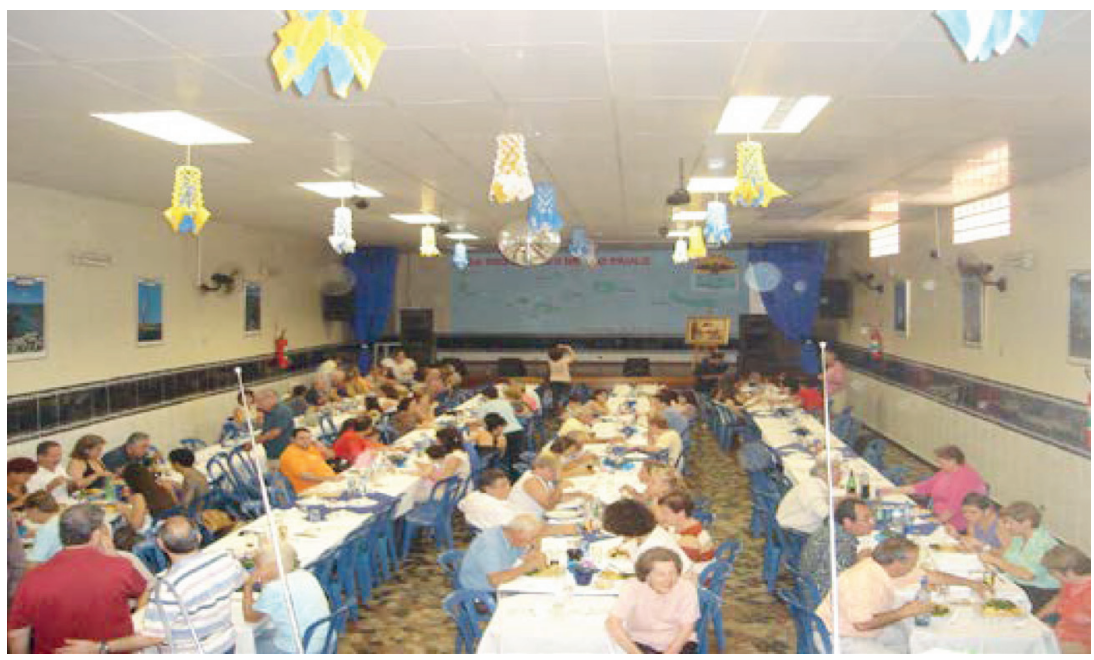

Fonte: Casa dos Açores de São Paulo, 2016. 
Nesse sentido, alguns sujeitos acompanham os formatos e as ressignificações da Casa e de seus próprios objetivos e significados ao longo dos anos, como menciona em depoimento dona Ilda Maria Salvador dos Reis (2008), ao comentar sobre sua vinda para São Paulo, sua relação com o trabalho fabril e o papel da Casa dos Açores:

É muito importante. Ajudo no que eu posso. Não sei se eu ajudo muito como elas porque eu vim com 13 anos, aí entrei na fábrica; então, chegava em casa e minha mãe já tinha tudo pronto. Então, não fazia muita coisa. Aí, agora, nós vamos fazendo; alguma coisa a gente pega, mas outras... Que nem a malassada... Não é fácil. 0 ponto dela no amassar é difícil. 0 difícil não é o amassar, é o ponto dela que é difícil de pegar. Eu gostaria que mais açorianos frequentassem. Não é só açoriano quanto brasileiro. A Casa tá aberta pra todos. Mas nós temos açorianos ainda muito retraídos, com receio de vir, sabe? Eu acho que isso não podia acontecer no nosso meio. Eu gostaria que viesse mais. Principalmente os filhos dessas... [refere-se aos filhos das mulheres que frequentam a casa e que fazem parte do grupo folclórico]. Mas aí acho que é uma coisa que vem de casa, porque, se você incentiva seus filhos desde pequeno e... A minha filha mais velha, ela não sabia o hino brasileiro, mas o português ela sabia quando ela entrou na escola, acho que isso não é certo, mas eu a ensinei pelo que eu sabia. Ela sabia cantar o hino nacional português, o brasileiro eu não sabia, então eu não ensinava.

Sobre sua função na Casa dos Açores, ela ajuda na elaboração das malassadas, prato típico açoriano. Em sua fala, também destaca a importância da transmissão para os filhos da manutenção das tradições, atribuindo sentido de continuidade do grupo e fortalecendo os vínculos com o imaginário da infância e da terra natal. Quanto à associação e sua frequência, faz um apelo para que outros envolvidos se interessem pela participação e por partilhar as tradições e memórias ali inscritas.

Em outros momentos de seu depoimento, observam-se as articulações com as origens, o momento da partida, a cidade de acolhimento e suas transformações, construindo, reconstruindo e reforçando representações, experiências, práticas e elos entre o passado e o presente. Dessa forma, observa-se que as identidades culturais passam por transformações constantes, não estando fixadas em um passado essencializado, mas estando sempre sujeitas ao contínuo "jogo" da história, da cultura e do poder (Hall, 2000).

Destacam-se entre as proposições dos mentores e diretores da Casa dos Açores possibilitar encontros entre os açorianos das diversas ilhas e as gerações de seus descendentes, buscando identificar os que migraram das ilhas e seus descendentes, bem como agregar brasileiros que possam contribuir para a associação. Nota-se que manter e divulgar as atividades da Casa dos Açores assume uma dimensão de luta para a preservação desse território para outras gerações, que nem sempre se interessam pela história de seus antepassados. 
Ao longo dos anos, as experiências coletivas ganharam destaque, fomentando o ingresso de associados, além de efetivar a missão da agremiação, que é manter o elo com os Açores, suas tradições e manifestações culturais. Na trajetória da investigação, foram realizadas visitas à Casa dos Açores, ${ }^{17}$ especialmente em momentos de festividade, em particular da Festa do Espírito Santo, podendo-se perceber a importância para a comunidade das atividades desempenhadas no âmbito do sagrado. 0 culto do Divino Espírito Santo e a festa em louvor a ele tornaram-se símbolos da açorianidade. ${ }^{18}$ Essa devoção religiosa encontra-se presente no cotidiano em práticas de sociabilidade e comensalidade, também nos momentos celebrativos, e tem sido perpetuada pelos açorianos em suas vivências nas diásporas (Angelo, 2017).

Nas festividades, observa-se que os sentidos da devoção ao Espírito Santo vinculam-se às tradições do cristianismo, sua construção simbólica encontra-se nos textos bíblicos, que destacam a composição da Santíssima Trindade com o Pai (Deus), o filho (Jesus) e o Espírito Santo.

Na fé católica, uma das representações do Espírito Santo é em forma de pomba branca, significando pureza, espiritualidade e iluminação, com referência a Pentecostes, momento por excelência para celebração do Divino. A festa de Pentecostes ocorre no quinquagésimo dia depois da Páscoa e é considerada um dos maiores acontecimentos da fé cristã, depois do Natal e da Páscoa.

As celebrações da Festa do Divino têm ancestralidade na cidade de São Paulo. Eram comemoradas na região central da cidade, na Capela do Espírito Santo (rua Frei Caneca). 0 festejo era realizado no bairro da Bela Vista e percorria outros bairros, chegando até a Barra Funda, onde havia muitos devotos. Os peditórios e ajutórios realizados de porta em porta visavam a angariar fundos a serem doados para carentes da cidade. Ao longo dos trajetos, eram feitas as folias, envoltas em danças, músicas, repentes e outras manifestações.

A festa profana constava comumente dos clássicos leilões de prendas, levantamento do indefectível "pau de sebo" e do "mastro", do Divino com as tradicionais salvas de "roqueira", queima de rojões e "fogueiras" que a sinonímia indígena converteu em "caiera" finalizando com o insubstituível "cateretê" entre a caipirada, e baile à europeia para os convidados mais grados do festejo, terminando tudo em opípara ceia para todos, na "casa do império", e farta distribuição de gêneros alimentícios aos pobres. (Freitas, 1985: 169-170)

Historicamente, a Festa do Divino foi constantemente recriada, algumas vezes por causa das restrições da Igreja e do Estado, ${ }^{19}$ controles que levaram à alteração de costumes, incluindo interdição das atividades de esmolar e também manifestações profanas do festejo, gerando a extinção de alguns elementos e a incorporação de novas práticas de religiosidade e culturais (Freitas, 1985). 


\section{Imagem 4 - Folias e foliões do Divino na Casa dos Açores de São Paulo}

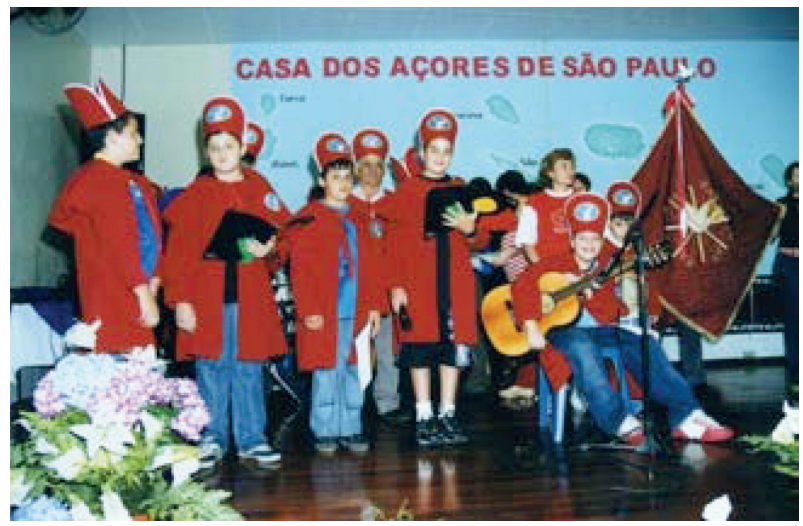

Fonte: Casa dos Açores de São Paulo, comemoração dos 31 anos de folias.

Os imigrantes trouxeram entre suas tradições celebrações que foram recriadas na sociedade de acolhimento (Jurkevics, 2005: 75), como o culto ao Divino e sua festa, além das folias e foliões do Divino, algo reinventado em São Paulo. Com o estabelecimento dos açorianos na Vila Carrão e adjacências, a festividade religiosa foi retomada (década de 1970), sendo vista como um elo identitário entre compatriotas, forma de reforçar as tradições e a religiosidade, sendo incorporados elementos da cultura açoriana, incluindo a festa e tudo o que nela se insere, como a culinária, os alimentos, as orações, a procissão, a coroação, entre vários outros aspectos.

No entanto, cabe esclarecer que, na maioria das vezes, as festas recriadas se baseavam em tradições das áreas rurais das ilhas e eram reconstituídas em um contexto diferenciado de uma metrópole, trazendo a necessidade de adaptações, implicando práticas distintas.

Conforme os relatos, nas últimas décadas, as atividades festivas do Divino foram se concentrando na Vila Carrão, e há mais de 40 anos a celebração religiosa inicia-se no domingo de Páscoa, 50 dias antes do domingo de Pentecostes.

Recuamos no tempo, estamos em 1975. Alguém, movido pela devoção ao Espírito Santo, vai aos Açores e de lá traz a primeira bandeira (já tinha a coroa). Este alguém chama-se Manuel Correia. Nesse mesmo ano, tem lugar a primeira Festa do Espírito Santo. Ele e a Antoninha vão falar com o padre Tiago para Ihe explicarem como tudo é feito nos Açores. No domingo de Pentecostes levam de carro os símbolos do Espírito Santo (coroa e bandeira), e na missa das 10h é feita solenemente a primeira coroação, tendo sido o hino do Espírito Santo tocado por disco. No fim das cerimônias, organiza-se uma pequena procissão e volta-se à casa do primeiro mordomo, o sr. Manuel Correia. No segundo ano, o mordomo foi o sr. Toninho do Ipiranga. Nesta festa já há império, com sortes, domingas e banda de música. Tudo isto despertou nos açorianos o 
amor e o carinho, há tanto tempo adormecidos, pelo Espírito Santo. A partir daqui muitas outras famílias maravilhosas se reuniram para continuar esta tão querida devoção. (Depoimento de Antonio Tavares Arruda, 21 jan. 2018)

Após sua criação, a Casa dos Açores de São Paulo passou a encabeçar as celebrações, participando ativamente da promoção do evento por intermédio de seus associados e da arrecadação de fundos ao longo do ano.

Já estávamos construindo a Casa dos Açores. Então, foi a primeira festa que foi feita em frente à Casa dos Açores, foi a minha. Foi legal. Geralmente, tudo que se faz lá eu sou geralmente o pioneiro, tudo leva meu apreço, tudo que eu puxo o negócio pra ver se aquele está mais sério que 0 anterior. Porque a gente estava na frente das casas dos mordomos, estava muito ruim, não dava pra fechar a rua, então não se tinha mais controle. Então, eu passei em 82, eu passei justamente pra Casa dos Açores, onde se faz os festejos, e dali pra frente foi sempre na Casa dos Açores. (Depoimento de Manuel de Medeiros, 3 jun. 2008)

A cada ano, a festa é organizada por um casal diferente, os "mordomos da festa", escolhidos e anunciados ao final do festejo anterior, momento em que já se iniciam os preparativos das comemorações para o ano seguinte. Nesse sentido, buscando angariar recursos e articular a comunidade, são organizados encontros religiosos, gastronômicos e festivos, como terços do Divino Espírito Santo, quermesse da festa, coquetel dos colaboradores, aniversário dos Açores, Revelando São Paulo (com a participação do grupo nas atividades no parque da Água Branca), Semana Cultural Açoriana, Natal. Nessas ocasiões, são servidos pratos como bacalhoada, massa sovada, cordeiro assado e cozido açoriano, além de se apresentarem grupos folclóricos, entre outras atividades.

A Festa do Divino Espírito Santo, para a comunidade de açorianos da Vila Carrão, é considerada uma festa luso-açoriana, com práticas religiosas e profanas, reunindo atividades como a reza diária dos terços durante sete semanas, alternando-se as rezas cantadas por homens e mulheres, nas quais é mantida a relação sagrada com os princípios dogmáticos do catolicismo, como seu calendário litúrgico, além de elementos novos, como o agradecimento pelos alimentos durante as atividades. As rezas, por sinal, mantêm elos com as práticas das ilhas, especialmente as de São Miguel e da Ilha Terceira, de onde veio a maioria dos açorianos.

Os terços são cantados à moda da Bretanha, Ilha de São Miguel. De igual forma, têm referência nesta ilha os demais procedimentos e/ou atividades da festa, tais como: as sortes; a folia com sua indumentária e cantoria típicas; a procissão; a missa da coroação; as linguiças e morcelas; as malassadas; a massa sovada etc., tudo isto fazendo parte desta importante festa, num grande processo de catalisação, que inclui também o culto ao Senhor Santo Cristo dos Milagres e à 
Virgem de Fátima, cujas imagens acompanham, ano a ano, a procissão do Divino, num grande festival de fé e de religiosidade, tipicamente açoriano. No encerramento do ciclo destes festejos é realizada uma grande festa de rua, à qual acorrem algumas dezenas de milhares de pessoas. Além de juntar toda a comunidade açoriana do bairro de Vila Carrão, as festividades agregam também açorianos dispersos pela cidade de São Paulo e municípios vizinhos, constituindo-se, assim, no grande encontro anual da comunidade açoriana na cidade de São Paulo. (Depoimento de Antonio Tavares Arruda, 21 jan. 2018)

As datas e os locais onde se realizam as rezas e os demais rituais da festa são previamente determinados. Os símbolos do Divino (coroa e bandeira) são levados para diferentes casas sorteadas a cada ano, sempre no último domingo de festa, conhecidas como "as domingas do Divino". Também nessas ocasiões ocorrem as Folias do Divino, feitas de improviso por repentistas que recolhem doações e cantam em agradecimento à comunidade.

No dia de Pentecostes, às 9h30 da manhã inicia-se a procissão, saindo da Casa dos Açores em direção à Igreja de Santa Marina, ${ }^{20}$ também na Vila Carrão, onde se realiza a missa em louvor ao Divino Espírito Santo. Durante o ritual religioso, sete crianças são coroadas e realiza-se o rito de bênção aos presentes em nome do Divino Espírito Santo.

As festividades continuam com a apresentação de grupos folclóricos, que alegram os visitantes com as antigas cantigas portuguesas e açorianas. Comidas típicas da gastronomia açoriana compõem a celebração, com destaque para as linguiças, alheiras, massas sovadas, malassadas e morcelas, além do vinho dos Açores, que são vendidos em barraquinhas durante as festividades.

Mesmo diante das mudanças ocorridas na cidade e na trajetória dos membros da comunidade (com o deslocamento de alguns para outros bairros), os açorianos reconhecem a importância e a necessidade da manutenção das tradições, reconstruindo de forma resistente elos entre o passado e o presente. Assim, a Festa do Divino se tornou um marco identitário, ${ }^{21}$ além de ser uma forma de garantir o vínculo com os Açores. Essa também é uma luta política de assentamento, significância e reconhecimento social; por mais que se reelabore ao longo dos anos, do mesmo modo, fornece subsídios para o enfrentamento dos diversos grupos no mosaico cultural.

A festa, os sujeitos históricos envolvidos e a representação cultural pertencente a esse grupo fizeram com que os traços da cultura açoriana, modificados e transformados, mantivessem reminiscências. Pensar a cultura como uma arena de aspectos conflituosos é tentar imergir nos significados do cotidiano desse grupo imigrante, verificando as experiências vivenciadas, as memórias, as festividades e a religiosidade dessa comunidade. 


\section{CONSIDERAÇÕES E POSSIBILIDADES}

preender cultura em movimento é tarefa complexa e desafiadora; tentar recuperá-la
perpassa por questões de ocultamento, por questionamentos sobre um processo movediço e sem contornos definidos, pois "a cultura em sua essência apriorística é um processo dinâmico, incessante de construção e reconstrução de invenção e reinvenção" (Flores, 2000: 13). Particularmente, a festa é momento de reconciliação; tanto o âmbito do sagrado como 0 do profano são condensados e unidos em harmonia (Berger, 1973).

Contudo, as gerações dos descendentes de açorianos não têm os mesmos padrões dos primeiros imigrantes. Observar movimentos intergeracionais permite perceber a carência de compreensão de certos significados das tradições e de seus momentos celebrativos de cunho religioso 22 e também revela conflitos entre permanências, manutenções, transformações e abandono das tradições, uma vez que estas são plásticas e aceitam inovações (Bosi, 1987).

A Casa dos Açores, com o intuito de manter as identidades e fomentar os laços com a terra natal e o passado, busca a conscientização dos jovens; no entanto, vem enfrentando diminuição gradativa de seus membros e de suas atividades. Um dos pontos críticos é o envelhecimento e a perda dos associados, que, com o avançar da idade, diminuem sua participação. Para se manter como instituição, procura motivar os jovens descendentes a participar das atividades, bem como abre-se ao ingresso de membros de origem não açoriana, além das ações de apoio estrategicamente implementadas pelo Governo dos Açores. ${ }^{23}$

Como elemento associativo, a Casa, desde sua intenção de criação, posiciona-se como um lugar de manutenção das identidades, em que se traz de volta o passado, ressignifica-se o presente e ponderam-se atitudes para que o futuro seja possível tanto nas ações interculturais com o Governo dos Açores quanto na organização dos associados e na integração dos grupos, seja nas atividades gastronômicas, religiosas ou sociais. O fortalecimento se dá, em grande medida, pelas gerações em interação, sociabilidade que já se mantém há mais de meio século.

Em sua trajetória histórica, a Casa dos Açores se constitui em um território de luta pelas identidades, de luta pelo espaço e mesmo de luta pela diversidade acoplada nos sentidos da saga imigrante açoriana, tornando-se uma possibilidade para pesquisas em vários temas como açorianidade, memórias da migração, cultura e patrimônio, identidade diaspórica, formação de redes transnacionais, comunicações virtuais, política cultural, formas de organização comunitária, além de permitir observar diferenças entre essa comunidade e outras inseridas em contextos diversos. 
Essa luta foi implementada pelos sujeitos históricos que se deslocaram dos Açores e construíram com suas próprias mãos a Casa dos Açores, criando a associação para que pudessem manter as memórias e tradições, dando continuidade às festas do Divino.

Contudo, ainda existem múltiplas outras histórias para serem contadas e diversificados processos de deslocamentos para serem desvendados. Novas investigações e interpretações poderão contribuir para reverter invisibilidades, cooperando no desvelar de memórias e histórias da e/imigração. A inclusão de uma perspectiva do associativismo (da experiência da Casa dos Açores de São Paulo) poderá ser favorável para recuperar as experiências desses sujeitos históricos.

\section{NOTAS}

1 Deve-se destacar a noção de territorialidade, identificando o espaço como experiência individual e coletiva, no qual a rua, a praça, a praia, o bairro, os percursos estão plenos de lembranças, experiências e memórias (Rolnik, 1992).

2 Na historiografia portuguesa, alguns pesquisadores, como Carlos Cordeiro e Artur Boavida Madeira, discorrem sobre os lugares no Brasil e as conjunturas de vinda, incluindo assentamentos e distribuições para os estados do Maranhão, da Bahia, do Pará, de São Paulo e de Minas Gerais, além de contínuas propostas que absorviam as necessidades que incentivaram os processos de saídas (Cordeiro e Madeira, 2003).

3 Verifica-se que, no século XX, os maiores picos de saída foram nos anos 1902, 1906, 1911, 1920, 1956, 1958, 1970 (sendo o maior em números) e 1975 (Cordeiro e Madeira, 2003).

4 o Cotonifício Guilherme Giorgi foi a indústria que mais admitiu açorianos e seus descendentes, na maioria das vezes arregimentados por cartas de chamada de parentes e conterrâneos.

5 Ver trabalhos de Ramella (1995), Tilly (1990) e Truzzi (2008).

6 Sobre o fluxo migratório da primeira metade do século XX, surgiu um novo tipo de movimento associativista, movido também pelo desejo de preservação da identidade e da memória, distinto das associações portuguesas (Oliveira, 2014).

7 o Conselho Mundial das Casas dos Açores foi formado pelos membros constituintes das Casas dos Açores de todo o mundo e efetivado por meio da Declaração da Horta, de 12 a 15 de novembro de 1997, sob o patrocínio do Governo Regional dos Açores, por meio do Gabinete de Emigração e Apoio às Comunidades.

8 Vários são os propósitos do governo dos Açores no que se refere à manutenção das identidades, como a criação de práticas inclusivas, projetos de promoção da interculturalidade e outros (Diário da Lagoa, 16 dez. 2015).

90 associativismo se relaciona com o núcleo familiar, a herança imigrante e com uma ideia de acolhimento dos patrícios (Nogueira, 1998).

10 A categoria tradição se refere aqui à "tradição inventada", ou seja, "um conjunto de práticas de natureza ritual ou simbólica que visam inculcar certos valores e normas de comportamento através da repetição, o que implica continuidade em relação ao passado" (Hobsbawm e Ranger, 1997: 9). 
11 As associações mutualistas e de socorros mútuos se proliferaram com o capitalismo no Brasil diante das dificuldades cotidianas de trabalho e de vida (Fortes, 1999; Luca, 1990).

12 As casas regionais representam manifestações culturais e identidades dos imigrantes e estão apoiadas em referências geográficas a partir de festas, símbolos, imagens, saudosismo da terra natal e outros sentidos (Sousa, 2005).

13 Cabe destacar a importância de se incluir a rua como território de vivências e memórias. Nos depoimentos, ela é referenciada como espaço material e também como espaço social, local de residência e convivência, exposição, procissão e festa; lugar de trocas, comércios, intercâmbios, reuniões e solidariedade; também de exclusão, manifestação e revolta (Garden, 2006: 5-17).

14 A categoria cotidiano parte da concepção de conjunto de operações singulares de indivíduos, sociedades e identidades. Nesse sentido, os sentidos de práticas cotidianas passam a valorizar as "artes do fazer" dos sujeitos e dos sentidos (Certeau, 2008).

15 A expressão comunidade imaginada foi cunhada por Benedict Anderson e se relaciona com uma abordagem antropológica de nação. Assim, 0 autor definiu nação como comunidade política imaginada implicitamente limitada e soberana (Anderson, 2008).

16 "Vodos ou bodos são entendidos como tradicional distribuição de comida aos pobres" (Abreu, 1999: 39).

17 A Casa dos Açores, ao buscar criar e recriar laços com seus compatriotas, com a comunidade luso-brasileira e com o público em geral, promove eventos e atividades, algumas tendo como fim angariar fundos para as práticas celebrativas e caritativas.

18 Açorianidade deve ser aqui entendida como um sentimento aflorado sobre as raízes que vai além do simples bairrismo, pois condensa a solidariedade e a união dos sujeitos oriundos do mesmo lugar. São aqueles que constituíram um estado de ser do "homem açoriano", com destaque ao e/imigrante que busca preservar suas raízes ilhoas (Nemésio, 1932).

19 As proibições pelas quais passaram as Festas do Divino se apoiavam na profanação de objetos sagrados, como é o caso das folias, que traziam em seu formato a dança e a música com as imagens de santos e padroeiros. Desde o século XVII que se estabeleceram regras para as festividades, proibindo-se profanações.

20 A Paróquia Coração Eucarístico de Jesus e Santa Marina, fundada em 8 de dezembro de 1946, faz parte da história da Vila Carrão e dos açorianos que vivem no bairro. Em sua maior parte, as atividades religiosas propostas pelos açorianos contam com o apoio do pároco e/ou são realizadas nessa igreja.

21 A Festa do Divino da Vila Carrão consta do Calendário Turístico Oficial da cidade de São Paulo (assim como as celebrações de outras comunidades de imigrantes).

22 A religião como núcleo firme da convivência impregnou as manifestações da vida social e, nesse sentido, as festas e manifestações religiosas transformaram-se em reunião social, sobretudo nas regiões rurais, dos engenhos e fazendas isoladas. Nesse momento, tanto o sagrado quanto o profano se uniram em fé e diversão (Wernet, 1987: 24-25).

23 "A estratégia de eventos da Casp tem mudado. Reduziram-se os eventos de almoços e jantares na sede, que ensejam muito trabalho e pouco retorno financeiro, para uma participação em eventos externos de grande porte, tais como o Revelando São Paulo, eventos em escolas e de outras comunidades emigradas. Esta estratégia deve ser ampliada, na medida em que vem apresentando melhores resultados" (Depoimento de Antonio Tavares Arruda, 21/1/2018). 


\section{REFERÊNCIAS BIBLIOGRÁFICAS E DOCUMENTAIS}

ABREU, Martha. O Império do Divino: festas religiosas e cultura popular no Rio de Janeiro, 1830-1900. Rio de Janeiro: Nova Fronteira; São Paulo: Fapesp, 1999.

ANDERSON, Benedict. Nação e consciência nacional. Rio de Janeiro: Ática, 2008.

ANGELO, Elis Regina Barbosa. As celebrações do Divino Espírito Santo: um elo entre Brasil e Açores nas relações de tradição e (res)significação da cultura. In: MEDEIROS, Lená Menezes de; SOUSA, Fernando (Org.). Brasil-Portugal: pontes sobre o Atlântico - múltiplos olhares sobre a e/imigração. Rio de Janeiro: Eduerj, 2017.

; MATOS, Maria Izilda Santos de. Imigrantes açorianos em São Paulo: tempos, tradições e transformações. In: MATOS, Maria Izilda Santos de; SOUSA, Fernando de (Org.). Deslocamentos \& histórias: os portugueses. Bauru: Edusc, 2008. p. 259-272.

BERGER, P. O rumor dos anjos: sociedade moderna e a descoberta do sobrenatural. Petrópolis: Vozes, 1973.

BOSI, Ecléa. Memória e sociedade: lembrança de velhos. São Paulo: T. A. Queiroz/Edusp, 1987.

CASA DOS AÇORES DE SÃO PAULO. Estatuto da Casa dos Açores de São Paulo. São Paulo, 1995. Disponível em: <http://casasdosacores.org/wp-content/uploads/2015/09/estatutos-CASP-antigos.pdf>. Acesso em: 13 abr. 2017.

CERTEAU, Michel. A invenção do cotidiano: artes de fazer. Petrópolis: Vozes, 2008. v. 1.

CONSELHO MUNDIAL DAS CASAS DOS AÇORES. São Paulo. [s.d.]. Disponível em: <http://casasdosacores.org/ casas-dos-acores/sao-paulo/>. Acesso em: 13 abr. 2017.

CORDEIRO, Carlos; MADEIRA, Artur Boavida Madeira. A emigração açoriana para o Brasil (1541-1820): uma leitura em torno de interesses e vontades. Arquipélago • História, 2. série, v. VII, 2003.

DIÁRIO DA LAGOA. Governo dos Açores assinala Dia Internacional dos Migrantes. Açores: Gabinete de Apoio à Comunicação Social/Presidência do Governo Regional dos Açores, 16 dez. 2015. Disponível em: <http:// diariodalagoa.com/arquivo/24727>. Acesso em: 22 jan. 2018.

FLORES, Maria Bernadete. Povoadores da Fronteira: os casais açorianos rumo ao Sul do Brasil. Florianópolis: EdUFSC, 2000.

FORTES, Alexandre. Da solidariedade à assistência: estratégias organizativas e mutualidade no movimento operário de Porto Alegre na primeira metade do século XX. Cadernos AEL: Sociedades Operárias e Mutualismo, Campinas, ed. 10-11, v. 6, 1999.

FREITAS, Afonso Antonio de. Tradições e reminiscências paulistanas (1868-1930). Belo Horizonte: Itatiaia; São Paulo: Edusp, 1985.

FREITAS, Sônia Maria de. Presença portuguesa em São Paulo. São Paulo: Imprensa Oficial/Memorial do Imigrante, 2006.

GARCIA, Sylvia Gemignani. Cultura, dominação e sujeitos sociais. Tempo Social: Revista de Sociologia da USP, São Paulo, v. 8, n. 2, p. 159-176, out. 1996.

GARDEN, Maurice. Histoire de la rue. Pouvoirs: Revue Française d'Études Constitutionnelles et Politiques, Paris, n. 116, p. 5-17, jan. 2006. Disponível em: <http://www.revue-pouvoirs.fr/Histoire-de-la-rue.html>. Acesso em: 17 out. 2016. 
HALL, Stuart. A identidade cultural na pós-modernidade. Rio de Janeiro: DP\&A, 2000.

HOBSBAWM, Eric; RANGER, Terence. A invenção das tradições. Rio de Janeiro: Paz e Terra, 1997.

JURKEVICS, Vera Irene. Festas religiosas: a materialidade da fé. História: Questões \& Debates, Curitiba, n. 43, 2005.

LUCA, Tânia Regina de. As sociedades de socorros mútuos italianas em São Paulo. In: BONI, Luis A. de (Org.). A presença italiana no Brasil. Porto Alegre: Fondazione Giovanni Agnelli, 1990. v. II.

MATOS, M. Izilda S. Portugueses: deslocamentos, experiências e cotidiano - São Paulo séculos XIX e XX. Bauru: Edusc, 2013.

NEMÉSIO, V. Açorianidade. Insula, Barcelona, n. 7-8, jul./ago. 1932.

NOGUEIRA, Ana Maria de Mora. Como nossos pais: uma história da memória da imigração portuguesa em Niterói, 1900/1950. Dissertação (Mestrado em História), Universidade Federal Fluminense, Niterói, 1998.

NORA, Entre memória e história: a problemática dos lugares. Projeto História, São Paulo, v. 10, p. 7-28, 1993.

OLIVEIRA, Antonio Henrique Seixas de. Associações e casas regionais portuguesas na cidade do Rio de Janeiro: lugares de memória. In: CONGRESSO INTERNACIONAL INTERDISCIPLINAR EM SOCIAIS E HUMANIDADES. Anais... Salvador, v. 6, n. 3, p. 50-66, 2014. Disponível em: <http://aninter.com.br/Anais\%20CONINTER\%203/GT\% 2006/04.\%200LIVEIRA.pdf>. Acesso em: 12 ago. 2017.

RAMELLA, Franco. Por un uso fuerte del concepto de red en los estudios migratórios. In: BJERG, María; OTERO, Hernán (Comp.). Inmigración y redes sociales en la Argentina moderna. Tandil: Cemla-IEHS, 1995. p. 9-21.

ROCHA-TRINDADE, Maria Beatriz. Associativismo em contexto migratório. Revista Migrações, Lisboa, n. 6, p. 39-58, abr. 2010.

ROLNIK, R. História urbana: história na cidade. In: FERNANDES, A.; GOMES, M. A. (Org.). Cidade e história: modernização das cidades brasileiras nos séculos XIX e XX. Salvador: Faculdade de Arquitetura da UFBA, 1992.

SCOTT, W. R. Institutions and organizations: ideas and interests. Los Angeles: Sage Publications, 2008.

SEYFERTH, Giralda. Imigração e cultura no Brasil. Brasília: Universidade de Brasília, 1990.

SOUSA, Roberto Ribeiro de. Representações geográficas de identidades: 0 caso das casas regionais de origem portuguesa no Rio de Janeiro-RJ. In: Simpósio Nacional sobre Geografia, Percepção e Cognição do Meio Ambiente. Anais... Londrina: Universidade Estadual de Londrina, 2005.

TILLY, Charles. Transplanted networks. In: YANS-MCLAUGHLIN, Virginia (Ed.). Immigration reconsidered: history, sociology and politics. Oxford: Oxford University Press, 1990. p. 79-95.

TRUZZI, Oswaldo. Redes em processos migratórios. Tempo Social, São Paulo, v. 20, p. 199-218, 2008.

VERONA, Antonio Folquito. O mundo é nossa pátria: a trajetória dos imigrantes operários têxteis de Schio que fizeram de São Paulo e do bairro do Brás sua temporária morada, de 1891 a 1895. Tese (Doutorado) — Faculdade de Filosofia, Letras e Ciências Humanas, Universidade de São Paulo, São Paulo, 1999.

WERNET, A. A igreja paulista no século XIX: a reforma de d. Antonio Joaquim de Melo (1851-1861). São Paulo: Ática, 1987. 


\section{DEPOIMENTOS ORAIS}

Antonio Tavares Arruda, 60 anos. São Paulo, 21 jan. 2018.

Henrique de Arruda Soares, 68 anos. São Paulo, 7 jul. 2008.

Ilda Maria Salvador dos Reis, 78 anos. São Paulo, jun. 2008.

Manuel de Medeiros, 61 anos. São Paulo, 3 jun. 2008.

Maria de Lurdes Arruda Paz, 73 anos. São Paulo, 2 nov. 2006.

Maria Joana Rezende Rodrigues, 78 anos. São Paulo, 2 out. 2008. 
